\title{
CONSTRUIR CON MADERA
}

\section{(CONSTRUCT WITH WOOD)}

Enrique Nuere, Dr. Arquitecto

ESPAÑA

\section{RESUMEN}

Las indudables ventajas que aporta la construcción en madera como contrapunto a las formas tradicionales de concebir la vivienda en general, se describen - de manera somera- en este artículo.

Se hace hincapié, asimismo, en la resistencia que presenta la madera en lo que respecta al paso del tiempo y frente al fuego, a diferencia de aquellas estructuras realizadas en acero, hierro u hormigón.
Fecha de recepción: 30-XII-97 $660-8$

\section{SUMMARY}

The undoubtful advantages that construction with wood has as a counterpoint to the traditional ways used in $d$ welling-houses are briefly described in this article.

Also it emphasizes the resistance of wood when facing fire and age, as compared to those structures made of steel, iron or concrete.

\section{Construir con madera}

En España nos parecen exóticas las casas construidas totalmente en madera, o lo que es peor, relacionamos la construcción en madera con la provisionalidad, algo más próximo a una barraca de feria que a una residencia digna.

Sin embargo, la casa construida con madera no tiene por qué desmerecer de la construida con cualquier otro material; es más, hoy puede alcanzar cotas más altas de calidad que nuestras construcciones tradicionales. Esto no sería así si los oficios no se hubieran degradado al nivel que lo han hecho, lo que hace muy dificil, sino imposible, encontrar albañiles como aquéllos que tan sólo hace treinta años conocían su oficio a la perfección.

Esta degradación del arte de bien construir ha desembocado en una situación en la que la pérdida de nuestra antigua tradición carpintera ya no es un handicap a la hora de comparar sistemas constructivos. Es triste tener que reconocerlo, pero ahora mismo ni hay buenos carpinteros ni hay buenos albañiles; puede haber excepciones, pero no hacen más que confirmar la regla. En estas circunstancias, tanto si usamos madera como si empleamos otros materiales, hay que aprender nuevas técnicas y formar nuevos oficios, lo que deja a la madera prácticamente en igualdad de condiciones respecto de otros materiales.

Es más, se pueden considerar una serie de ventajas a favor de la madera como material principal a emplear en la construcción de la vivienda. Me refiero naturalmente a la vivienda unifamiliar, solución a la que la mayoría de los españoles no estábamos habituados, por preferir tradicionalmente la propiedad horizontal, en bloques de altura. Pero primero fueron las casas para el verano en los alrededores de las ciudades, después la oferta creció exponencialmente con el desarrollo imparable del parque automovilístico, lo que permitía poder utilizar estas viviendas todos los fines de semana. Más tarde llegó la crisis del petróleo y este fenómeno se estancó, pero la misma crisis contribuyó a que muchas de esas segundas residencias empezaran a convertirse en vivienda permanente, a lo que ayudó eficazmente una decidida política de fomento del ferrocarril de cercanías. Así, sin pretenderlo, el español se fue convirtiendo en habitante suburbano y la vivienda unifamiliar empezó a ser un producto habitual en el mercado de la vivienda.

Pero nuestros hábitos constructivos no han cambiado, y seguimos construyendo del mismo modo que hace cientos 
de años, aunque complicando el proceso con instalaciones que antes no existían ¿Qué ocurre, por tanto, durante la construcción de una de estas viviendas unifamiliares de nuestros días?

En primer lugar tenemos que contratar los servicios de un arquitecto y de un aparejador, que, como es lógico, no vivirán cerca de la futura obra, lo que empieza a dificultar el posible control de la construcción y, en el mejor de los casos, a encarecerlo. Supongamos que tenemos la suerte de contratar las obras con un contratista local (que probablemente también vivirá a algunos kilómetros de la obra). Para que la coordinación de los diferentes oficios que habrán de intervenir en el proceso constructivo pueda ser real, sería preciso contar con un jefe de obra o un encargado que estuviera todo el tiempo en ella, pero el volumen de la construcción no ofrece un margen económico suficiente que permita pagar este gasto, por lo que, como mucho, contaremos con un oficial de albañilería, más o menos despabilado, que se encargará de dicha coordinación.

Cuando llega el fontanero, el electricista o el calefactor, querrán realizar su trabajo en el menor tiempo posible y, en la mayor parte de los casos, planteando situaciones conflictivas entre unos y otros, por lo que a la primera ocasión "tirarán por la calle de en medio", sin esperar a que el aparejador o el arquitecto, que son los únicos que pueden conocer cómo ha de ser el resultado final, puedan opinar sobre las soluciones idóneas. Por muy buena voluntad que pongan todos los que intervienen, el resultado nunca será óptimo y el precio siempre más alto que el deseable.

Todo lo anterior -sin poner en entredicho la dudosa eficacia de algunos obreros cuando no les ve su jefe-, redunda en carestía y mala calidad. Para garantizar un mínimo de eficacia se pueden contratar los trabajos por el sistema de destajos, método que, sin embargo, incide de forma muy negativa en la calidad final de la obra. No he mencionado el efecto adicional que sobre el coste representan las inclemencias del tiempo, cuando no afectan a la seguridad de la obra, por ejemplo a la resistencia del hormigón en tiempo de heladas, etc.

Es evidente que la mayor parte de los problemas enunciados se podrían evitar si el trabajo se pudiera realizar en un taller, a cubierto de riesgos meteorológicos y aprovechando al máximo el rendimiento de la mano de obra, que no sólo se controla en cuanto a su eficacia sino que también se evitan los problemas de descoordinación que se plantean sistemáticamente en las obras tradicionales.

Aquí es donde la madera puede aportar una eficaz ayuda. No se trata de construir casas tipo cabañas canadienses o finlandesas, ni siquiera casas que se vea que son de madera, sino de utilizar las ventajas que la madera ofrece para poder prefabricar de modo ligero. No necesitamos inventar nada, basta utilizar cualquiera de los sistemas probados en otros países, sin más que adaptarlos a nuestra idiosincrasia, lo que hoy por hoy no es tan sencillo, pero afortunadamente no imposible.

Aunque ya he anticipado que la falta de oficiales preparados no es una excusa para no construir con madera, tampoco debemos apoyarnos en la idea de que España es un país sin tradición en el empleo de la madera como elemento estructural importante; ejemplo de ello es la construcción urbana de ciudades como Madrid, donde se ha utilizado tradicionalmente no sólo para hacer pisos (donde era insustituible hasta la aparición del acero laminado), sino también en la realización del esqueleto entramado que soportaba toda la

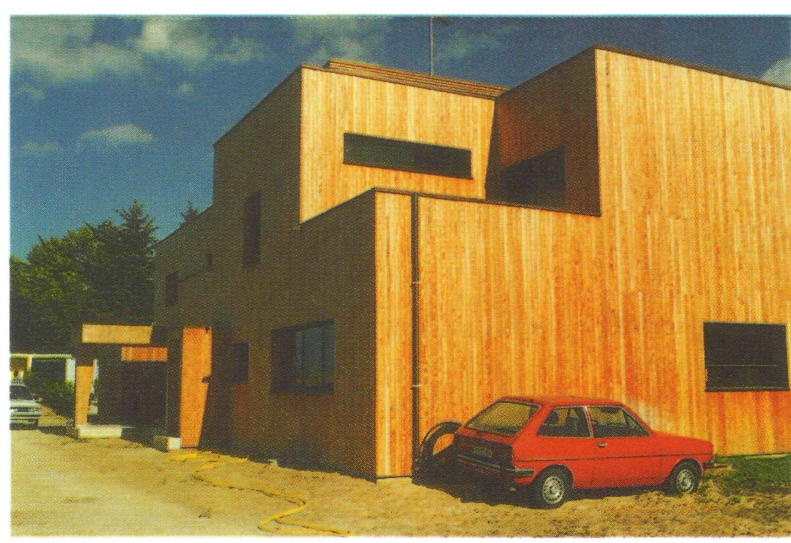

La construcción en madera puede ser evidente como en este caso, pero, con independencia del efecto estético buscado, la gran ventaja de emplear este tipo de material es su ligereza, que facilita cualquier proceso de prefabricación.

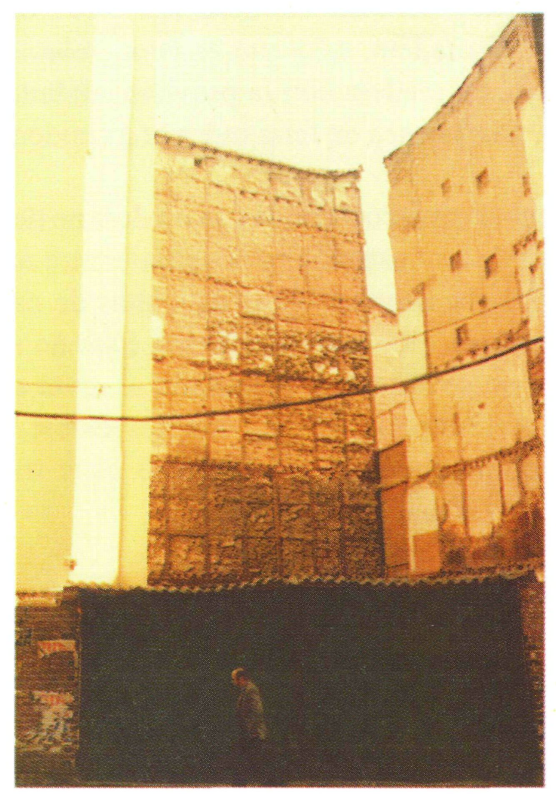

Ciudades como Madrid cuentan con un gran patrimonio de construcción entramada en madera, con estructuras que, con frecuencia, alcanzan seis o más plantas sobre la rasante. 
construcción. Los arquitectos vemos esto claramente cuando intervenimos en rehabilitaciones de edificios antiguos, incluso en los construidos durante el primer tercio de nuestro siglo. Las medianerías con entramado resistente de madera son una imagen familiar de los solares madrileños cuando se produce alguna demolición en el casco, o incluso en su antiguo ensanche.

Pero no se trata de recuperar sistemas que han sido superados por técnicas actuales y, sobre todo, no se trata de intentar competir en la construcción urbana de altura, sino de buscar soluciones para la vivienda unifamiliar que cada vez es más habitual, ya sea por cambio de gustos de la sociedad, o por imperativo inevitable. En este campo, la madera permite la realización de una gran parte de los trabajos necesarios en talleres especializados.

La primera gran ventaja que ofrece un sistema de prefabricación en taller es la de poder conseguir un efectivo control de calidad, tanto de lo realizado allí, como de la parte que deba de montarse en obra, ya que al acortar de forma drástica el tiempo de construcción, permite pagar los gastos de un técnico cualificado que se encargue de supervisar los imprescindibles trabajos que han de realizarse in situ.

Estos controles permiten garantizar los presupuestos de coste estimados, lo que contribuye a ajustar los márgenes de beneficio, que en la obra tradicional eleva el constructor de modo considerable para evitar "pillarse los dedos", aunque paradójicamente, a pesar del sobreprecio pagado, al final el constructor consigue beneficios reales muy bajos $y$, a veces, incluso pérdidas, lo que incide de modo muy negativo en posibles atenciones de garantía.

Pero hay más factores a favor de la madera. Las grandes capitales ven cómo el precio del suelo sube irremisiblemente (ejemplo que tratan de imitar incluso las pequeñas). En Madrid se puede llegar a pagar por el derecho a edificar un metro de vivienda, tres o más veces el coste de su construcción, y es un hecho irremediable que la capacidad de edificar en un terreno está perfectamente reglada y limitada por normas urbanísticas, que, en definitiva, son las que establecen el precio del suelo.

Supongamos que construimos una casa de $100 \mathrm{~m}^{2}$, con su estructura de madera, y una planta de $10 \times 10 \mathrm{~m}$. Con una construcción tradicional, sus muros perimetrales, más uno intermedio para apoyo del forjado superior-o de la cubierta- ocupan una superficie de $40 \times 0,35+10 \times 0,25$, es decir, $16,5 \mathrm{~m}^{2}$. Utilizando una estructura resistente de madera esa superficie puede ser de $40 \times 0,18+10 \times 0,10$, equivalente a $8,2 \mathrm{~m}^{2}$. La decisión de escoger la madera proporciona una ganancia de superficie útil en la vivienda de $8,3 \mathrm{~m}^{2}$, lo que permite ganar un dormitorio de tipo medio, o requerir menor superficie de terreno en la misma proporción. En una zona próxima a Arturo Soria, por poner un ejemplo, ese ahorro puede representar en este momento cerca de un millón y medio de pesetas.

Quien no frecuenta una obra de las que hacemos hoy en día no es consciente de la cantidad de material que se destroza en el proceso constructivo tradicional y el volumen de escombro que se genera. No sólo derrochamos el coste de ese material destrozado, sino que hemos de pagar jornales adicionales para limpiar constantemente las obras y para trasladar los escombros a los vertederos.

No menos interesantes son los ahorros que pueden conseguirse en aislamiento térmico, con su correspondiente contrapartida en el consumo de combustible para la calefacción, o el ahorro que se consigue en la cimentación al ser considerablemente menores las cargas que se transmiten al terreno, todo ello al margen de la enorme libertad de diseño que permite al arquitecto su enorme ligereza.

Existen por tanto importantes razones económicas que abogan por la construcción en madera ¿Qué nos impide entonces ponerla en práctica?

Aquí es donde interviene nuestra idiosincrasia. Ya he comentado que asociamos la madera en la construcción con algo deleznable. Nos gusta que nuestras casas sean eternas, lo más parecido a las pirámides, y la piedra y el ladrillo son los materiales que más nos acercan a nuestra idea de una morada ideal. Nadie duda que un gran palacio de cantería será más duradero que una casa de madera, pero, con independencia de que en nuestros días pudiéramos pagar la construcción con nobles sillares de piedra, ¿las casas que hoy se construyen con ladrillo son realmente más duraderas que las que pueden construirse con madera? ¿Quién puede garantizar que las viguetas de hormigón empleadas en los forjados actuales no sufran de aluminosis? ¿O que esas minúsculas fisurillas -frecuentes en elementos de hormigón- no vayan a provocar, tarde o temprano, la oxidación de las armaduras de hierro que garantizan su estabilidad? $¿ \mathrm{O}$ que el subsuelo en el que hemos construido nuestro sólido edificio no provoque asientos diferenciales que agrietan sin cesar el edificio debido al enorme peso de la construcción tradicional?, etc.

Los forjados de hoy ya no son de madera, son de acero o de hormigón, la estructura resistente tampoco es de madera, en los muros, al acero y al hormigón pueden acompañar las fábricas de ladrillos, que ya no son aquellos ladrillos sólidos de otros tiempos, sino más bien aire rodeado de unas delgadas capas de arcilla, mejor o peor cocida, en aras de abaratar el producto. Lo cierto es que hemos abandonado los buenos hábitos de la construcción tradicional, y dudo que alguna casa construida en las últimas décadas pueda convencerme de que durará varios siglos, mientras que edificios de estructura de madera ya nos lo han demostrado con creces. Por poner un ejemplo, la techumbre de la catedral de Teruel cumple ahora 737 años y no creo que 


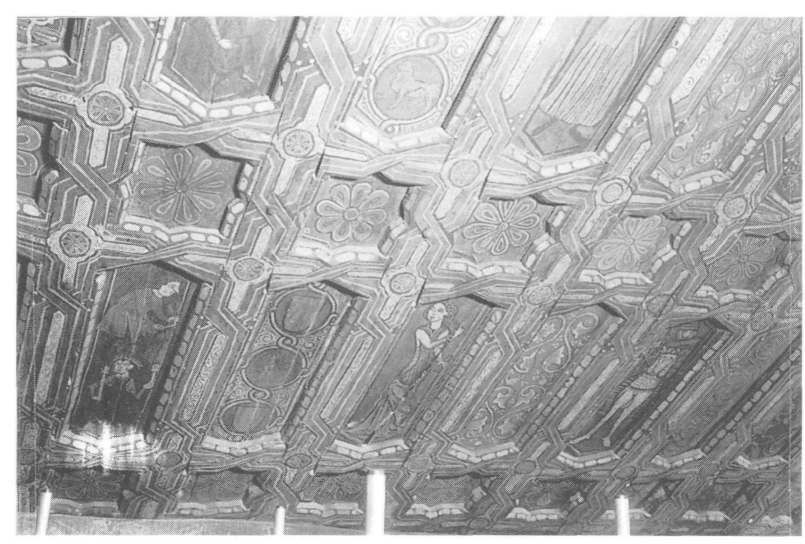

Aunque inconscientemente confiemos más en el acero o en el hormigón que en la madera, ninguno de estos materiales modernos pueden ofrecernos ejemplos de permanencia por siglos y siglos como puede hacerlo la madera. La techumbre de la catedral de Teruel, tras más de setecientos treinta años de estar en pie (sin que apenas se le hayan proporcionado cuidados en ese dilatado lapso de tiempo), ha pasado airosa una reciente inspección que prueba que puede seguir resistiendo años y años.

tuviera excesivos cuidados a lo largo de los siglos pasados, es más, la llegaron a despreciar hasta el punto de ocultarla tras una bóveda. Sin embargo, cuando se descubrió, por los años veinte de nuestro siglo, mejor o peor seguía cumpliendo su función protectora.

Quedan otros miedos en lo que respecta a la madera, por ejemplo el del fuego. Es curioso que no se sepa que el edificio más seguro para resistir un fuego sea el de madera. Los incendios hoy no se producen en las estructuras, sino en lo que contienen en su interior. Antiguamente existían focos de fuego en los edificios. Cada "hogar" disponía de su propio fuego, inicialmente se cocinaba en un fuego abierto, que también proporcionaba confort en tiempo frío, más tarde vinieron las cocinas económicas que domesticaban en gran medida el fuego cotidiano, al tiempo que permitían un importante ahorro de leña o carbón, pero, en cualquier caso, las casas estaban surcadas por una red de chimeneas por las que, sin cesar, pasaban los gases calientes de la combustión. Estas chimeneas se ahumaban y acumulaban en sus paredes hollines que había que desprender de tiempo en tiempo con ayuda de los deshollinadores. La tarea de limpieza de las chimeneas podía provocar roturas en sus paredes que, a veces, dejaban algún elemento de la estructura en contacto directo con los gases calientes, donde, su acción continuada, podía llegar a provocar la inflamación espontánea de la madera y dar comienzo, así, a un peligroso incendio.

Hoy esta situación ha cambiado, siendo, el principal causante de los fuegos, la electricidad, un cortocircuito, o un cable sobrecargado pueden iniciar un fuego, pero rara vez lo hará inflamando un elemento estructural de madera. Si el fuego se produce y el foco se encuentra cerca de un elemento resistente de la estructura, si éste es de madera es evidente que se quemará, pero conviene saber qué pasa, comparativamente, con elementos resistentes de otros materiales.

Nadie duda de que sometida a un fuego la madera se quema, pero su bajo coeficiente de transmisión del calor hace que en su interior permanezca inalterada. Esto se ve favorecido por la capa de madera que el fuego va carbonizando, que aún disminuye más la baja conductividad de la madera. El resultado, en cualquier caso, es que el fuego consume ese elemento a razón de $0,7 \mathrm{~mm}$ por minuto, lo que permite garantizar un tiempo de evacuación, o de actuación de los equipos de extinción, sin más que sobredimensionar las secciones de madera, por ejemplo: $2 \mathrm{~cm}$ de demasía en la sección garantizan la necesaria resistencia durante $30 \mathrm{minu}$ tos.

La mayor parte de la gente prefiere una estructura de hierro o de hormigón para evitar este peligro, pero veamos que pasa si el elemento era de hierro. A los cinco minutos de exposición al fuego, el hierro ha perdido el $50 \%$ de su capacidad resistente y, además, se ha dilatado de forma importante, provocando esfuerzos en sus uniones para las que no está preparado. Antes de 10 minutos el elemento pierde la necesaria resistencia y provoca el colapso de la estructura sin que hayamos tenido tiempo de reaccionar. Todos recordarán el terrible accidente sufrido por un grupo de bomberos en el incendio de Saldos Arias de Madrid. La razón principal fue la de que entraron a apagar un fuego en un edificio de madera en el que sabían que podían confiar, pero sin percatarse que pasaban a una zona en la que la estructura se había sustituido, en una reforma anterior, por vigas de hierro.

Si el elemento afectado es de hormigón el tiempo de resistencia es algo mayor, pero los resultados son similares. Tan pronto como se resquebraja la capa de hormigón que protege al hierro, éste se calienta mucho más rápidamente $\mathrm{y}$, al ser buen conductor, su calor se transmite por su interior, dilatándose muchísimo más que el hormigón, lo que provoca la disgregación brutal del elemento y el hundimiento parcial de los contiguos.

En definitiva, si el miedo al fuego podía influir en nuestro rechazo a la madera como material de construcción, más miedo tendremos que tener al acero o al hormigón, más propicios a pillarnos desprevenidos, en caso de incendio, que la madera, que aguantará con nobleza a que nos pongamos a salvo.

¿Pero, tan sólo tenemos rechazo hacia la madera? Es evidente que no, no hay nadie que se encuentre incómodo en una vivienda de madera, tal vez en climas muy cálidos pueda apetecernos más rodearnos de materiales más fríos como el mármol o la cerámica, pero incluso en estos climas apreciamos una buena puerta de madera, una buena tarima o un lujoso artesonado. Por otra parte el hecho de utilizar la 


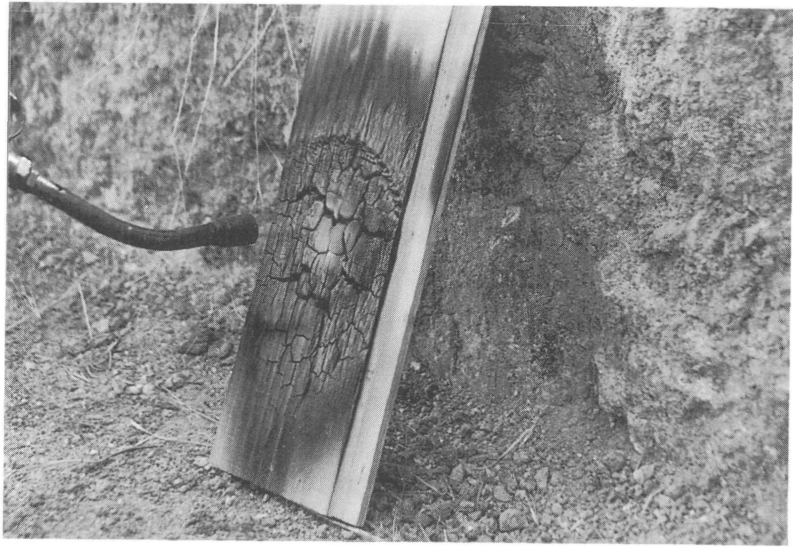

La madera es combustible, pero puede protegerse fácilmente contra la propagación del fuego mediante productos ignifugantes. En este ejemplo vemos una tabla sometida a la acción sostenida de un soplete, sin que se produzca llama en la madera. La propagación del fuego al resto de la pieza precisaría de la acción directa y sostenida de un foco de fuego externo.

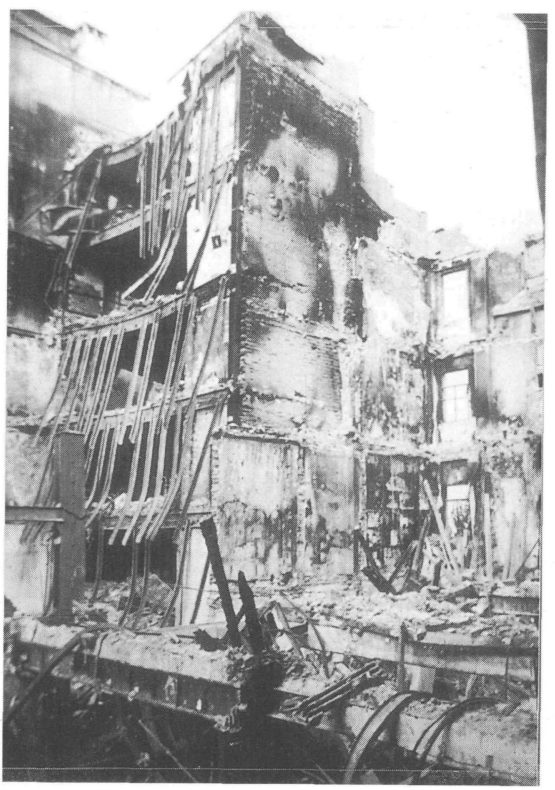

En el edificio de Almacenes Saldos Arias de Madrid se habian realizado reformas, escogiendo el acero para sustituir parte de la estructura de madera existente. Mientras la estructura de madera soportó un importante incendio hasta la llegada de los bomberos, no ocurría lo mismo con la estructura más nueva, de hierro, que se colapsó sistemáticamente.

madera como elemento de construcción no quiere decir que este material haya de ser omnipresente. Podemos construir una casa de madera cuyos acabados lo oculten, ya por dentro, ya por fuera, o en ambos casos.

Pero aunque quisiéramos prescindir totalmente de la madera en nuestras viviendas, las puertas de paso siguen siendo todavía de madera, aunque en muchos casos la madera con que se fabrican tan sólo son virutas o partículas aglomeradas con cola, pero, hoy por hoy, no existe alternativa en

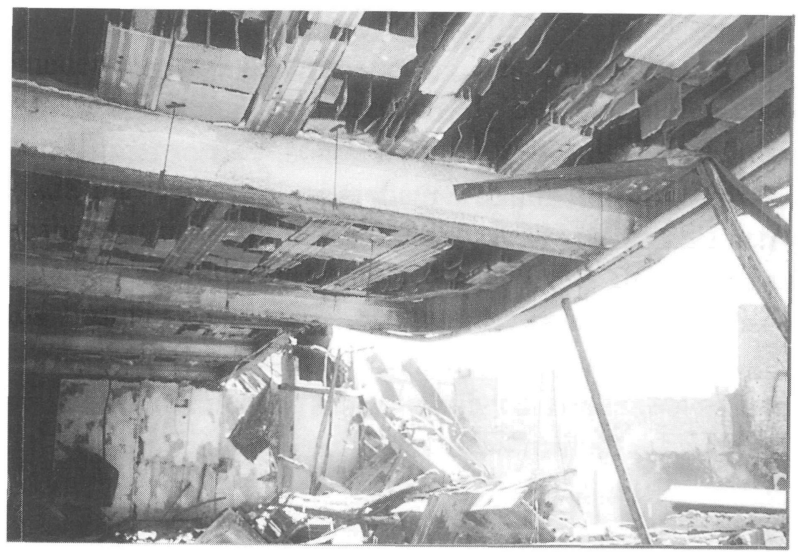

El hormigón tampoco ofrece mejores garantías contra el fuego. Poco más de media hora es lo que pudo resistir, sin colapsarse, esta estructura mixta de hierro y de hormigón del Palacio de Congresos de Madrid.

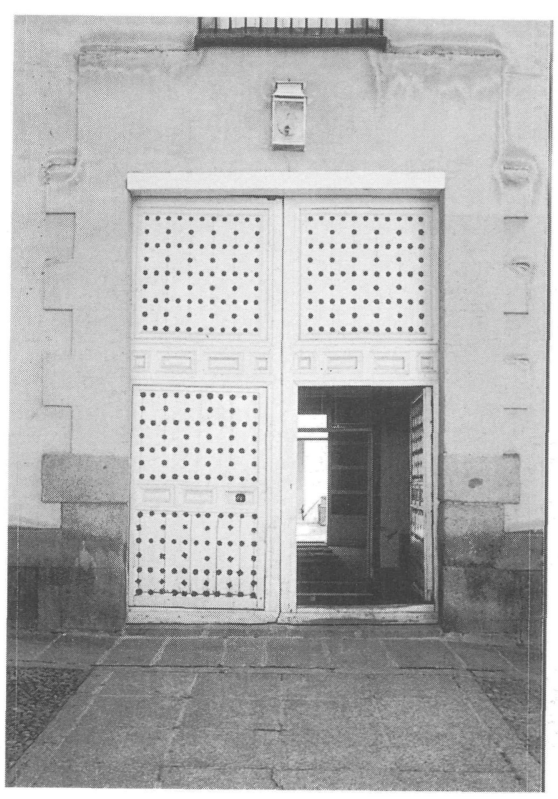

A la hora de construir una puerta, la madera sigue siendo el material universalmente preferido.

nuestro mercado que compita con la madera o sus derivados para este fin.

Pueden quedar aún ciertas reticencias al uso de la madera, como, por ejemplo, la creencia de que su empleo en la construcción puede acabar con los bosques existentes. Nada más lejos de la realidad. Con los bosques pueden acabar los usos agrícolas o los ganaderos. La roturación para conseguir tierras de cultivo ha sido la gran enemiga de los bosques. Todos conocemos el afán incendiario de 
algunos ganaderos gallegos para cambiar bosque por pasto, y cómo una política decidida puede atajar este problema. El peligro de los fuegos no provocados se ataja con un cuidado de los bosques durante los inviernos, y estos cuidados se llevan a cabo allí donde la madera es un bien a explotar. Un buen ejemplo de eficaz prevención de incendios lo tenemos en la sierra de Guadarrama, donde las explotaciones tradicionales de pino silvestre permiten pagar los trabajos de limpieza y mantenimiento de estos bosques, lo que permite que los fuegos no alcancen enormes proporciones y puedan ser atajados de forma eficaz.

Por otra parte, aunque en España careciéramos de madera, que no es el caso, siempre podremos importarla de las zonas del norte europeo y americano, donde se practican métodos de explotación que garantizan la pervivencia e incluso el aumento de las masas forestales. En Finlandia, por ejemplo, los pinos, abetos y abedules crecen de forma espontánea con la misma facilidad que la hierba en la cornisa cantábrica. Zonas que se han sometido a una tala exhaustiva son auténticos bosquecillos tan sólo 6 ó 7 años después, con algunos ejemplares que llegan a cinco metros de altura. Si además de esta facilidad de crecimiento espontáneo, se controla que se plante o regenere más de lo que se corta, como ocurre en estos países, la extinción de los bosques es imposible.

Sin necesidad de llegar tan lejos, en nuestra cornisa cantábrica se está fomentando un racional uso del pino insignis, no tan bueno como el silvestre, pero que como contrapartida admite mejor los tratamientos de defensa frente a xilófagos, y que en el corto plazo de treinta años permite su aprovechamiento maderero.

La última reticencia que encuentro con frecuencia es la creencia de que los españoles nunca hemos tenido tradición carpintera y que difícilmente podremos competir con nuestros vecinos europeos en este campo. Ante esta afirmación hemos querido mostrar alguno de los ejemplos de nuestra carpintería histórica, que, sin ánimo de exagerar, pueden codearse con las mejores realizaciones europeas de todos los tiempos, no tratándose de obras aisladas buscadas con lupa, sino parte de un riquísimo conjunto carpintero desgraciadamente poco valorado y menos conocido ¿Qué nos impide, entonces, volver a construir con madera?
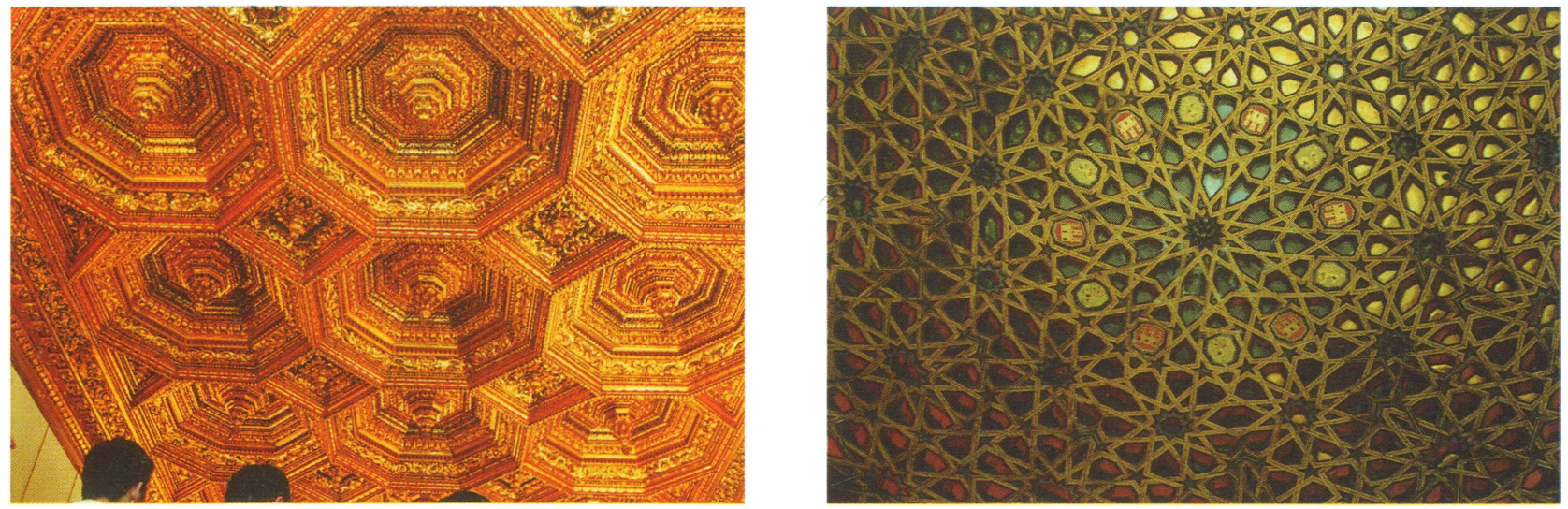

En la carpintería histórica española tenemos muchos ejemplos de magnificas obras realizadas en madera, que, tras varios siglos de existencia, han llegado en perfecto estado hasta nuestros dias. Vayan como botón de muestra de nuestra buena tradición carpintera estas dos, pertenecientes, respectivamente, al Palacio de la Generalitat Valenciana (izquierda) y a los Reales Alcázares de Sevilla (derecha). 